\title{
DESIGN E TERRITÓRIO: estudo de iniciativas de valorização da cultura gastronômica
}

\author{
Krucken, Lia; PhD \\ Universidade do Estado de Minas Gerais \\ lia.krucken@gmail.com \\ Miranda de Oliveira, Paulo; PhD \\ Universidade do Estado de Minas Gerais \\ paulo.miranda@uemg.br
}

Silva, Elisangela Batista da; MSc

Universidade do Estado de Minas Gerais

lili_batistabh@yahoo.com.br

Ibarra, Maria Cristina.; MSc

Universidade do Estado de Minas Gerais

mariacih@gmail.com

Silva, André C. M.; Mestrando

Universidade do Estado de Minas Gerais andremol@gmail.com

Luz, Daniela; Especialista

Universidade do Estado de Minas Gerais dane.luz@gmail.com

Bellardi, Ravi; Graduando

Universidade do Estado de Minas Gerais ravibellardi@gmail.com

Resumo: O objetivo desse artigo é identificar possíveis ações e estratégias do design na valorização do território e dos recursos relacionados à gastronomia regional, no contexto da Economia Criativa, a partir da seleção e análise de um conjunto de iniciativas. Inicialmente apresenta-se o referencial teórico que fundamenta as discussões em torno das contribuições do design para a valorização do território. São apresentadas e analisadas quatro iniciativas: Instituto Atá, no Brasil, La Jeune Rue, na 
França, Grandma's Design, na Holanda, e Eataly, de origem Italiana. O resultado obtido a partir da análise é um conjunto de potenciais focos de atuação do designer na valorização da cultura gastronômica do território.

Palavras-chave: design e território, gastronomia, economia criativa, projetos colaborativos.

\begin{abstract}
The aim of this paper is to identify possible design actions and strategies in the valorization of territory and its local gastronomy resources in the context of creative economy, based on the selection and analysis of some particular initiatives. Firstly, we present the theoretical framework that underlies the discussions about the contributions of design in territory valorization. Four initiatives are presented and analyzed: ATÁ Institute, in Brazil, La Jeune Rue, in France, Grandma's Design, in the Netherlands, and Eataly, from Italy. The result obtained from the analysis is a set of potential focuses where designers could act in relation to the gastronomic culture valorization of a territory.
\end{abstract}

Keywords: design and territory, gastronomy, creative economy, colaborative projects.

\title{
1. INTRODUÇÃO
}

No contexto da economia criativa, a proposta desse artigo é refletir sobre as estratégias de design na valorização do território e dos recursos ligados à gastronomia regional a partir de projetos de caráter colaborativo.

Esse trabalho é parte do projeto de pesquisa "Valorização sustentável da cultural e da gastronomia do território: projeto Sabores do Velho Chico (uma bacia criativa)", em desenvolvimento junto à Escola de Design da Universidade do Estado de Minas Gerais, com apoio do CNPq/Ministério da Ciência e Tecnologia e do Ministério da Cultura.

Num primeiro momento fundamentam-se as discussões em torno das contribuições do design para a valorização de um território e de seus recursos gastronômicos baseados em referencial teórico. Na sequência são apontados os procedimentos e métodos adotados. São expostas e analisadas quatro iniciativas e, a partir da análise, são indicadas ações e estratégias do design nesse contexto.

\section{REFERENCIAL TEÓRICO}

Apesar do conceito tradicional da geografia, só muito recentemente o território constituiu-se como objeto de investigação e projeto em outras áreas. Especialmente no Brasil, devido a sua riqueza em termos de diversidade cultural e de recursos do ecossistema, o debate sobre a valorização do território é crucial. A necessidade de desenvolver estratégias para proteger e valorizar os conhecimentos plurais e os recursos naturais - buscando alternativas de transformação e renovação do território e das tradições - representa uma grande responsabilidade e constitui um desafio para pesquisadores e profissionais.

A abordagem do design aplicada ao território visa beneficiar simultaneamente vários produtores e empresas localizados em uma determinada região geográfica. Isto 
significa planejar ações que valorizem conjuntamente o capital territorial e o capital social, em uma perspectiva duradoura e sustentável em longo prazo.

Muitas oportunidades podem surgir ao mudar o foco de análise: de uma empresa para um conjunto de empresas, das competências e dos recursos de uma organização para as competências e os recursos situados em um território. Desta mudança de paradigma emergem muitas possibilidades de sinergia entre os produtores e as empresas que, ao interagir, fortalecem e/ou complementam suas capacidades. Nessa perspectiva, podem surgir ações e projetos colaborativos. Certamente é necessário que haja um intuito empreendedor favorável, que resultará da intenção e da capacidade dos empresários em: a) associar-se e trabalhar em conjunto; b) desenvolver uma visão estratégica dos recursos do território e de projetos para valorizá-los; e c) conduzir ações em nível sistêmico e desenvolver redes favoráveis ao desenvolvimento local. Outros fatores fundamentais referem-se as possibilidades do território relacionadas a infra-estrutura e tecnologia da informação, bem como o acesso ao mercado e a comunicação das qualidades locais em produtos que possam ser apreciados por diferentes grupos de consumidores.

A economia criativa quando propõe a valorização econômica de bens e serviços com base no conhecimento, na criatividade e no capital intelectual (HOWKINS, 2013), se relaciona diretamente com a proposta de valorização do território. Para Barreto (2012) "o design é um tema transversal em todas as áreas da economia criativa, ao transmitir a identidade regional e agregar valor ao produto". O autor ainda destaca a importância de se investir neste segmento como "uma ferramenta de inovação, de geração de negócios e de acesso a novos mercados".

O interesse no território como foco central de vantagens competitivas e inovativas, a partir da década de 1970, é destacado por Lastres et al. (2002). Segundo Cassiolato e Lastres (2001), "a aglomeração de sistemas produtivos locais tem auxiliado pequenas e médias empresas a ultrapassarem conhecidas barreiras ao crescimento das firmas, a produzirem eficientemente e a comercializarem produtos em mercados distantes - quer nacionais ou internacionais".

O sucesso de algumas experiências de economias regionais impulsionou o investimento em arranjos produtivos, dentre as quais podemos citar os distritos industriais das regiões da Lombardia, Toscana, Veneto e Emília Romagna na Itália, de Valência e Catalunha na Espanha, de Baden Wurtenberg na Alemanha, do Norte de Sidney na Austrália e do Vale do Silício na Califórnia. No Brasil, algumas iniciativas expressivas são: moda íntima feminina em Nova Friburgo, cachaça em várias regiões de Minas Gerais e em Abaíra, na Bahia, acessórios em couros e sapatos em Campina Grande, móveis em Ubá, calçados de Nova Serrana, frutas do Pará, cerâmica de Mato Grosso do Sul e mel do Maranhão, dentre outros.

Como facilitador do processo de inovação, o design representa um importante coadjuvante no desenvolvimento econômico e sócio-cultural. O desafio é canalizar forças (reconhecidas e latentes) presentes no território e apoiar um comportamento pró-ativo versus a colaboração e integração de interesses locais, de forma que as inovações se concretizem e tragam benefícios coletivos. Com base em alguns autores (FRANZATO, KRUCKEN E REYES, 2013; KRUCKEN, 2009, BELLARDI, KRUCKEN E MOARES, 2010) foram identificados alguns processos que o design pode facilitar e dar suporte. São eles: 
a. identificação e exploração sustentável do potencial dos recursos e das competências situadas no território;

b. projeto e desenvolvimento de produtos e serviços diferenciados e com alto valor agregado localmente, com base nos recursos, nas competências disponíveis e na riqueza cultural;

c. processos colaborativos de inovação e aperfeiçoamento do design local, promovendo o diálogo entre tradição e inovação e fortalecendo o sentido de pertença da comunidade;

d. promover o desenvolvimento de uma cultura de co-produção de valores e de processos produtivos colaborativos;

e. fortalecimento da imagem do território e de seus produtos e empresas;

f. projeto de novas interfaces e formas de intermediação entre os produtores e entre produtores e consumidores (redes e cadeias de valor), envolvendo os recursos e potencialidades das empresas e do território;

g. resgate de valores e da cultura local e desenvolvimento de produtos a partir de matérias-primas alternativas disponíveis no território e a utilização de subprodutos e resíduos;

h. estreitamento de relações com instituições de ensino e pesquisa e outras organizações locais, interagindo com profissionais de diversas áreas de conhecimento no investimento compartilhado em pesquisa e na busca conjunta por soluções inovadoras.

i. promover os alimentos típicos e o universo gastronômico local no âmbito da cultura, imprimindo neles identidade territorial.

Para os casos estudados entendeu-se também que estratégias e técnicas do design de serviços podem valorizar a gastronomia regional através de ações que promovam a inovação, a colaboração entre os atores locais e sua promoção em diferentes cenários.

\section{PROCEDIMENTOS E MÉTODOS}

O desenvolvimento deste estudo é baseado em pesquisa bibliográfica e análise de iniciativas relacionadas à valorização do território por meio de seus recursos gastronômicos e culturais. O ponto de partida para a pesquisa delineou-se a partir da seguinte questão: "Quais métodos e ferramentas de design podem ser usados para mapear, registrar e difundir a gastronomia regional, de forma criativa e interessante para diferentes públicos?"

Foram selecionadas 4 iniciativas: Instituto Atá, La Jeune Rue, Grandma's Design e Eataly. O quadro 1 apresenta uma breve descrição dessas iniciativas e do foco de atuação. 
Quadro 1 - Breve descrição das iniciativas selecionadas e analisadas.

\begin{tabular}{|c|c|}
\hline $\begin{array}{l}\text { Iniciativa, } \\
\text { local de origem }\end{array}$ & Breve descrição e focos das iniciativas \\
\hline $\begin{array}{l}\text { Instituto ATÁ, } \\
\text { Brasil }\end{array}$ & $\begin{array}{l}\text { Essa iniciativa do chef de cozinha Alex Atala desenvolve atividades para o } \\
\text { levantamento, divulgação e incentivo à produção de ingredientes típicos da } \\
\text { cultura culinária brasileira com foco na Amazônia e no Cerrado. O Instituto ATÁ } \\
\text { constitui uma organização sem fins lucrativos, não possui sede física e pode ser } \\
\text { acessado por meio do website http://www.institutoata.org.br. Dez sócios com } \\
\text { formações e atuações profissionais diversas compõem o Instituto ATÁ. Residindo } \\
\text { em diferentes partes do Brasil, a maioria dos sócios desenvolve projetos paralelos } \\
\text { que dão suporte ao Instituto. }\end{array}$ \\
\hline $\begin{array}{l}\text { La Jeune rue, } \\
\text { França }\end{array}$ & $\begin{array}{l}\text { Iniciativa francesa, idealizada pelo banqueiro Cédric Naudon e pelo chef Antonin } \\
\text { Bonnet, que iniciou-se em } 2012 \text { com a compra de diversos imóveis do século XVIII, } \\
\text { na região do Alto Marais em Paris. Essa região passou por um processo de } \\
\text { revitalização que envolveu diversos designers famosos e fabricantes locais para } \\
\text { realizar neste local um resgate de tradições. A proposta visa contribuir para } \\
\text { preservar o patrimônio gastronômico; oferecer produtos saudáveis cultivados de } \\
\text { forma sustentável; valorizar o savoir-faire francês (saber fazer); e promover a } \\
\text { discussão em torno da produção e do comércio de alimentos. A divulgação das } \\
\text { ações do projeto é feita por meio do website http://lajeunerue.com/ }\end{array}$ \\
\hline $\begin{array}{l}\text { Grandma's } \\
\text { Design, Holanda }\end{array}$ & $\begin{array}{l}\text { O projeto nasceu a partir de um concurso organizado em } 2013 \text { pelo grupo } \\
\text { holandês Vol-au-vent, que desafiou aos designers, chefs, e artistas a criar novos } \\
\text { conceitos ou produtos na área do 'food design'. Tem como foco proteger e } \\
\text { valorizar as tradições culinárias, bem como promover novas interpretações aos } \\
\text { saberes tradicionais relacionados à gastronomia. Foi organizada uma publicação } \\
\text { com os projetos vencedores, que podem ser acessados na plataforma virtual } \\
\text { http://www.grandmasdesign.com. }\end{array}$ \\
\hline $\begin{array}{l}\text { Eataly, } \\
\text { Itália }\end{array}$ & $\begin{array}{l}\text { Apresenta-se como uma alternativa ao sistema de distribuição e comercialização } \\
\text { de produtos alimentícios, tendo como foco a valorização de ingredientes e da } \\
\text { produção artesanal italiana. A Eataly é uma iniciativa que disponibiliza espaços } \\
\text { físicos e uma plataforma virtual (http://www.eataly.com), a partir dos quais os } \\
\text { visitantes podem conhecer, experimentar, consumir e/ou comprar produtos de } \\
\text { alta qualidade. Oferece programas de capacitação relacionados à enogastronomia } \\
\text { (cursos, livros e atendimento customizado). }\end{array}$ \\
\hline
\end{tabular}

\section{ANÁLISE DAS INICIATIVAS}

Cada uma das iniciativas foi estudada de modo a identificar: foco, modo de funcionamento, estratégias de design utilizadas, resultados obtidos e aspectos relacionados à sustentabilidade ambiental, social, cultural e econômica. Apresentamse na sequência algumas considerações.

A primeira iniciativa estudada foi o Instituto ATÁ, que propõe-se a estruturar cadeias e buscar ingredientes "de uma cozinha que não fosse somente boa de comer, mas que fosse saudável pra quem faz, pra quem come e pra quem produz" (ATALA, 2014). Os objetivos da iniciativa foram identificados como: levantar ingredientes e estudar sua aplicação e valorização gastronômica, divulgar estes ingredientes ampliando sua demanda e conscientizando diferentes públicos sobre sua origem, e assim aumentar a demanda destes ingredientes valorizando seus territórios de origem. A Figura 1 ilustra alguns destes aspectos. 


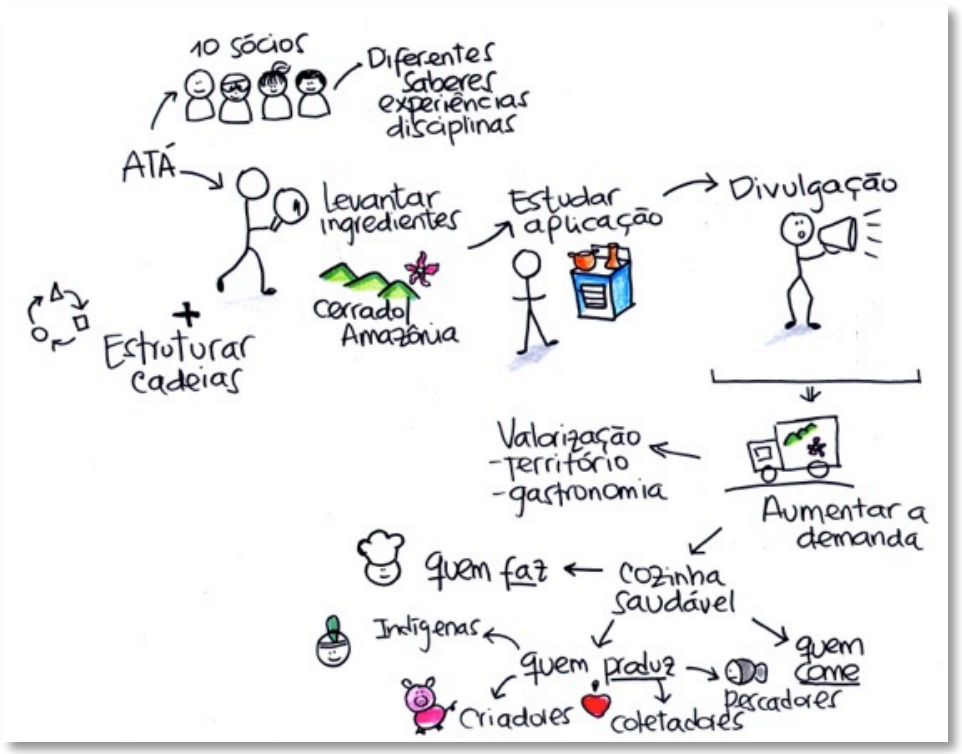

Figura 1 - Representação de aspectos envolvidos na iniciativa Instituto Atá. Fonte: "elaborado pelos autores com base em pesquisa realizada".

Um dos fatores relevantes para o sucesso do Instituto ATÁ é o fato de ser formado por uma equipe transdisciplinar. Atala (2014) afirma que percebeu que "era fundamental a participação de outros saberes, de outras expertises, de outras disciplinas para colocar em prática todo o potencial da oportunidade que estava a minha frente". Assim chef, engenheiro, empresário, designer, fotografo, antropólogo, jornalista e publicitário compõem um grupo criativo que trabalha em conjunto para planejar e realizar as ações do ATÁ, identificando potenciais, desenvolvendo estratégias, projetando atividades, executando projetos e analisando resultados. A publicação de um manifesto, em português e baniwa (língua indígena), pode ser apontada como uma ação inovadora na promoção da valorização da cultura gastronômica e na necessidade de "aproximar o saber do comer" (Figura 2).

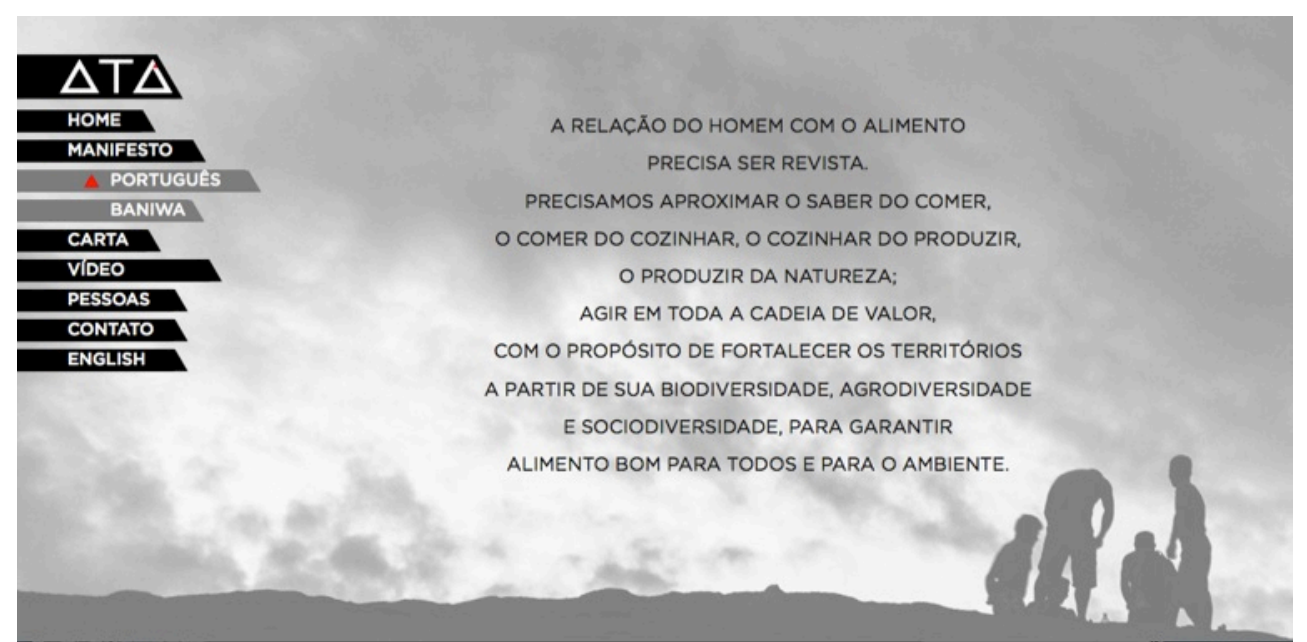

Figura 2 - Manifesto publicado pelo Instituto Atá. Fonte: http://www.institutoata.org.br, 2014.

La Jeune rue (a rua jovem) foi a segunda iniciativa estudada (Figura 3). Deverá iniciar as suas atividades em abril de 2014, e está previsto o funcionamento de uma queijaria de produção artesanal que utilizará o leite cru no preparo; uma padaria que 
irá plantar, colher e moer o trigo utilizado em sua produção; um açougue; uma peixaria de pequenos pescadores; um supermercado e um mini mercado de frutas e legumes cultivados no método da permacultura. A proposta dos idealizadores é replicar o conceito da Le Jeune Rue em outros lugares no futuro.

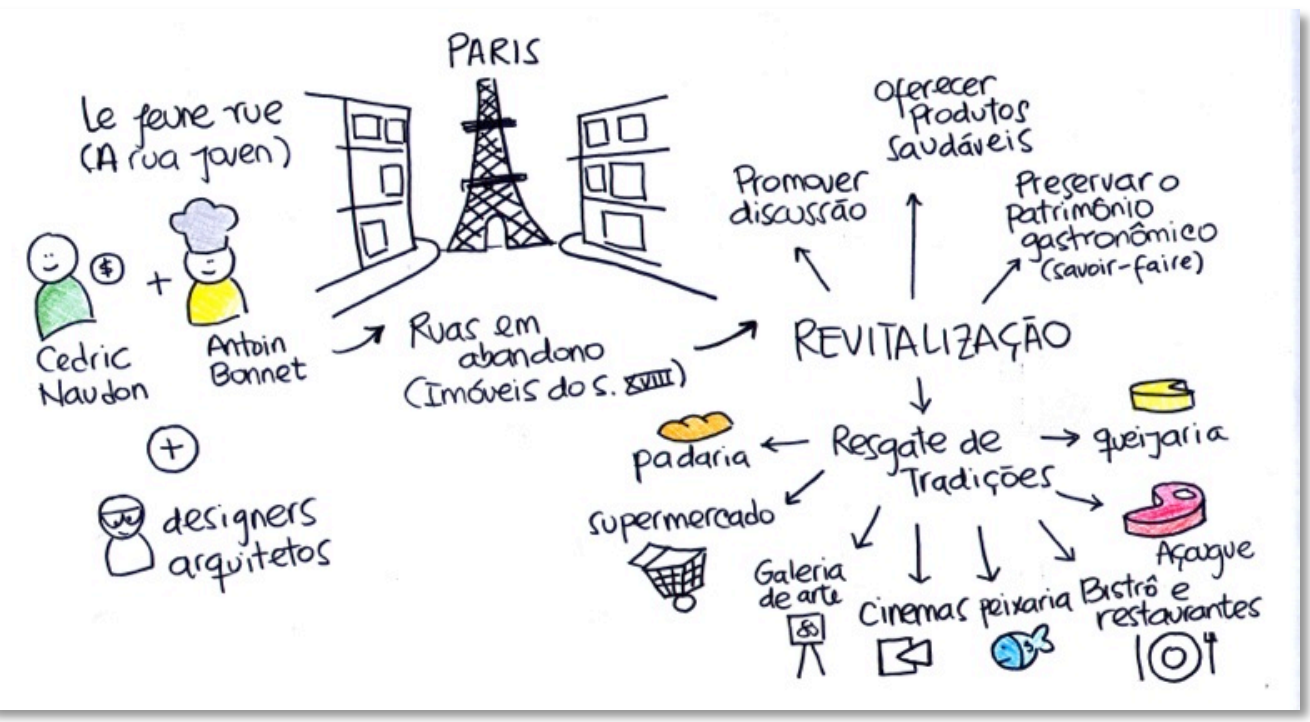

Figura 3 - Representação de aspectos envolvidos na iniciativa Jeune Rue. Fonte: “elaborado pelos autores com base em pesquisa realizada".

Um dos pontos fortes dessa iniciativa é promover a revitalização de uma região urbana que estava em abandono, valorizando a história local e possibilitando a reconstrução e o compartilhamento de conhecimentos do modos de fazer francês (Figura 4). A proteção e a valorização do patrimônio gastronômico se dá através do resgate das tradições em espaços projetados por designers para promover experiências significativas para produtores e consumidores.
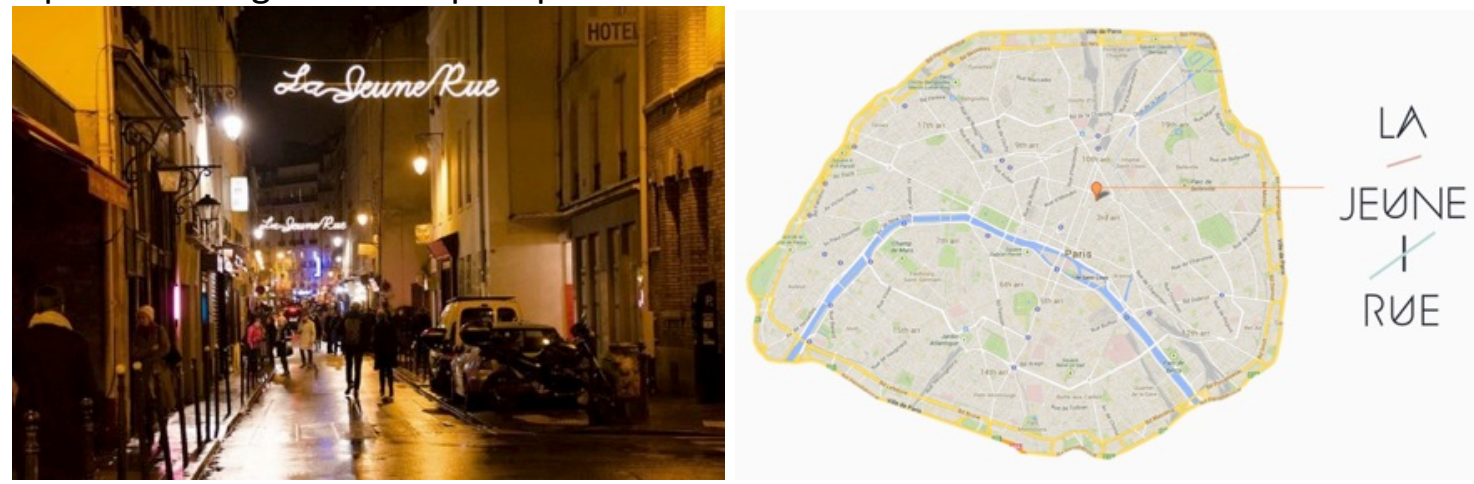

Figura 4 - Vista da Jeune Rue. Fonte: http://www.designboom.com, 2014.

O terceiro caso investigado foi o projeto Grandma's Design (Figura 5), um concurso organizado em 2013, que desafiava aos designers, chefs, e artistas a criar um novo conceito ou produto na área do food design. Estes tinham que ser inspirados em uma das entrevistas feitas a mais de 75 avós de 5 países (Bélgica, Países Baixos, Finlândia, Turquia e Itália), enquanto preparavam uma receita típica da confeitaria de seu país ou região e falavam da sua relação com ela. Apresentaram-se ao concurso 44 propostas e 5 foram selecionadas. Os designers ganhadores e as avós "inspiradoras" 
foram apresentados numa cerimônia de premiação e os projetos publicados no livro "Food inspires design" publicado em novembro de 2013, com apoio do Programa de Cultura da Comissão Europeia.

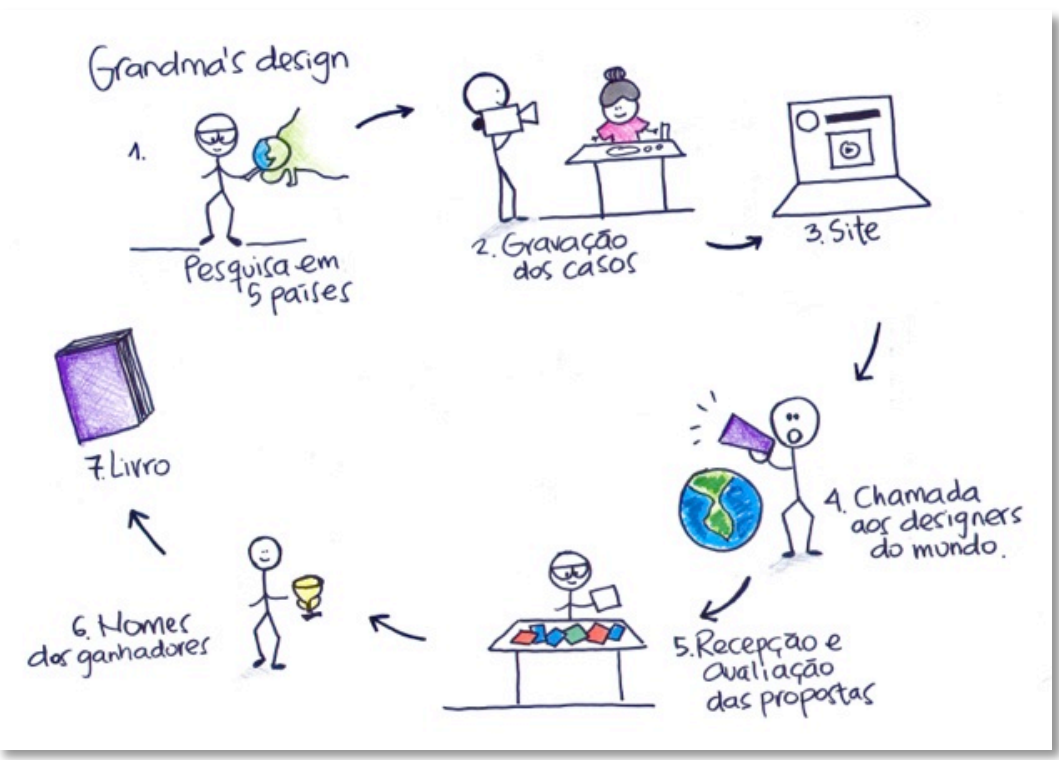

Figura 5 - Representação de aspectos envolvidos na iniciativa Grandma's Design. Fonte: “elaborado pelos autores com base em pesquisa realizada".

Um aspecto inovador importante dessa proposta foi juntar duas gerações (as avós, como exemplifica a Figura 6, e jovens designers) com o objetivo de incentivar a conservação de formas de fazer ligadas à culinária de um território. Destacam-se como pontos fortes, relacionados ao design: a visualização de soluções, a materialização de conceitos e a interação com os participantes e o público em geral.

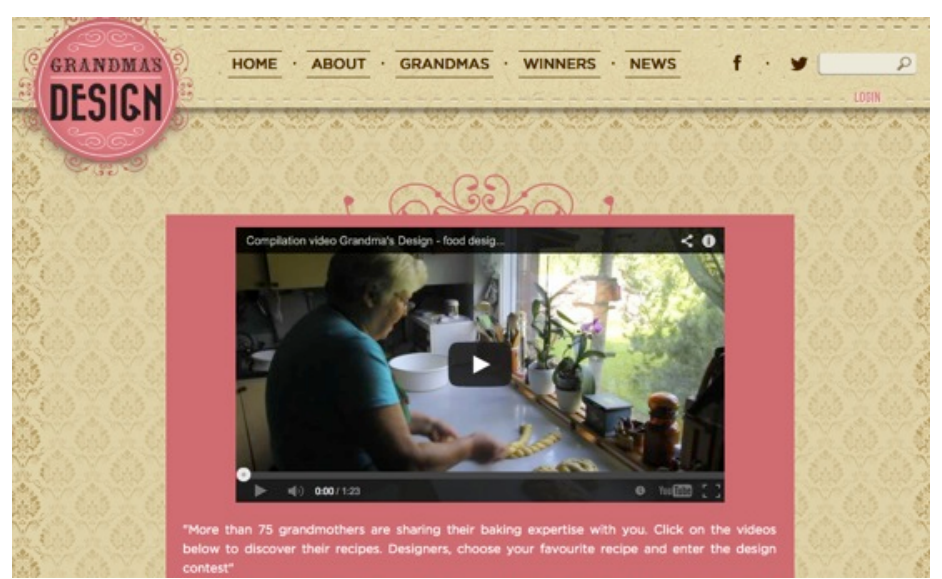

Figura 6 - Exemplos dos vídeos apresentados para inspiração de projetos de design para alimentos. Fonte: http://www.grandmasdesign.com, 2014.

A quarta iniciativa investigada foi a Eataly (Figura 7), que teve seu início em Turim e atualmente possui filiais em mais 9 cidades da Itália e unidades em Nova York, Chicago, Tóquio, Dubai, Istambul (ao fim de 2014, estará também presente em São Paulo). Esse empreendimento baseia-se em conceitos de sustentabilidade, responsabilidade e partilha, visando oferecer uma seleção de alimentos de alta qualidade a preços acessíveis ao público. Os produtos oferecidos são de excelência da 
enogastronomia artesanal e podem ser comprados ou consumidos nos próprios restaurantes dos estabelecimentos. Uma ação da Eataly a ser destacada é a oferta de serviços de educação especializada nas lojas, por meio de workshops e cursos, e ensino universitário junto à Universidade de Ciências Gastronômicas de Pollenzo. A Eataly vêm se estabelecendo como centro de referência da cultura italiana e de valores contemporâneos relacionados a questões das cadeias de valor dos alimentos.

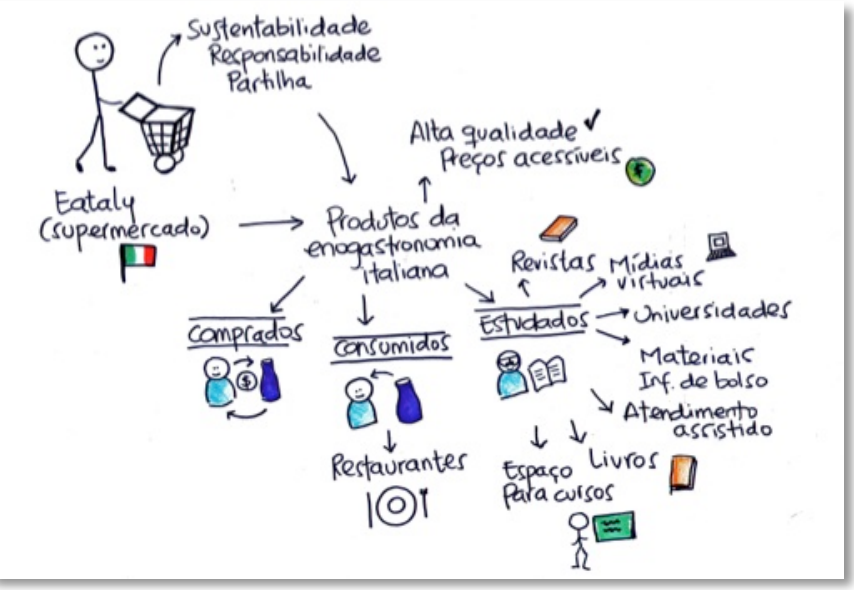

Figura 7 - Representação de aspectos envolvidos na iniciativa Eataly. Fonte: "elaborado pelos autores com base em pesquisa realizada".

Considerando a orientação da Eataly de proporcionar imersão e transparência na experiência da cultura enogastronômica italiana e as suas relações com os sistemas e cadeias de valor dos alimentos e bebidas, podem-se destacar alguns pontos relevantes da atuação do designer. Partindo de uma visão global, o designer atua na tradução dos conceitos e valores da Eataly em cadeias de valor, sistemas de produção, comercialização, consumo e descarte, gestão de marcas, projeto de experiências, serviços e ambientes, desenvolvimento de produto, materiais gráficos e de mídia virtual (Figura 8).
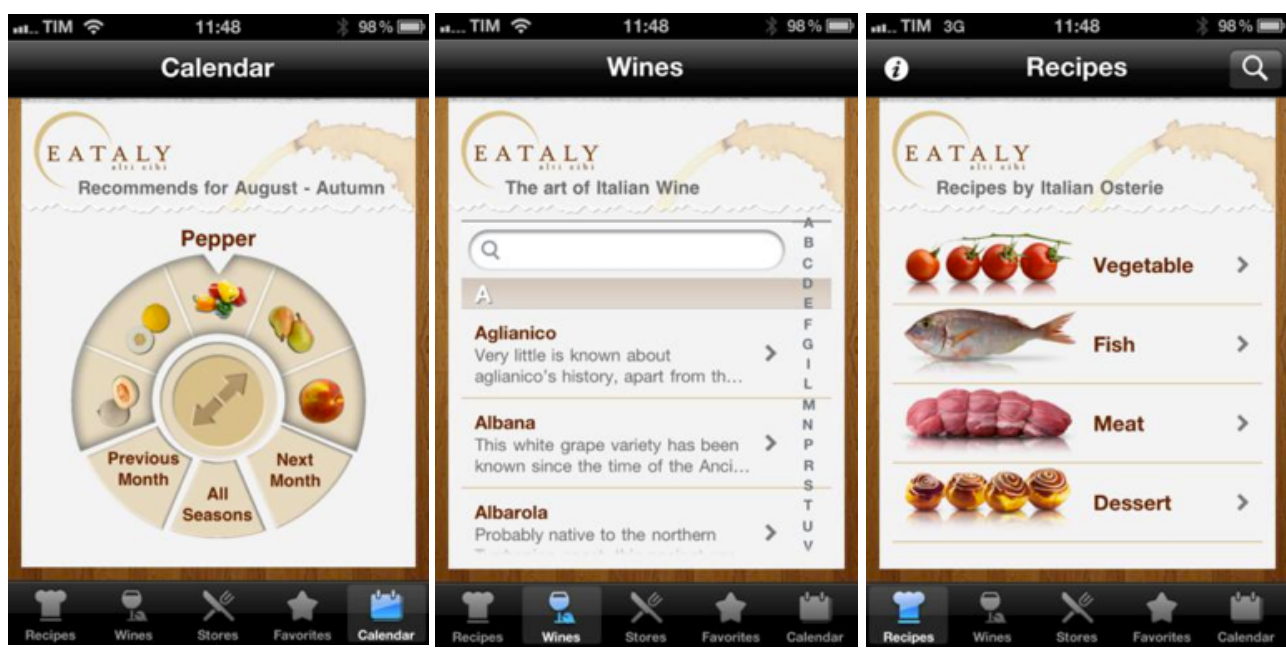

Figura 8 - Exemplo de produto desenvolvido pela Eataly - aplicativo para dispositivos móveis, que disponibilizam receitas, informações específicas sobre os alimentos e bebidas, como proveniência, sazonalidade, propriedades organolépticas e disponibilidade nas lojas. Fonte: App Store Apple, 2014. 
A partir da análise das iniciativas foi possível identificar algumas possíveis ações do design para valorizar a gastronomia de um território, apresentadas a seguir.

\section{CONSIDERAÇÕES FINAIS}

As iniciativas estudadas refletem a crescente conscientização sobre a importância do território e dos valores que são incorporados na produção artesanal local. Refletem, também, um crescente interesse dos consumidores em vivenciar experiências relacionadas à gastronomia. Como consequência, o desenvolvimento de estratégias de comunicação são cruciais para estimular e manter um intenso fluxo de informações entre produtores, consumidores e também designers. Planejar e promover a comunicação, portanto, são algumas das ações do design mais evidentes com o objetivo de promover o desenvolvimento local. Esse aspecto é fortemente presente nas iniciativas Instituto Atá, , La Juene Rue, Grandma's Design e Eataly.

Várias ações de design podem contribuir para impulsionar a cultura local, protegendo "o saber fazer gastronômico" como parte da identidade territorial. Podese observar esse aspecto nas quatro iniciativas estudadas. Outros potenciais focos de atuação são:

a) Desenvolvimento de aplicativos em linguagem próxima aos usuários (iniciativa Eataly);

b) Design de espaços e serviços relacionados à alimentação (iniciativas Eataly, La Jeune Rue);

c) Re-significação do saber fazer, aliando tradição e inovação (iniciativas Grandma's Design e Instituto Atá);

d) Design de experiência centradas na gastronomia, como é o caso das quatro iniciativas.

Por fim, destaca-se a importância da atuação transdisciplinar no desenvolvimento de soluções inovadoras para a valorização da cultura gastronômica de um território. Projetos de pesquisa nesse âmbito devem buscar a interação entre profissionais de diferentes áreas - gastronomia, design, gestão, comunicação, turismo, dentre outras.

Neste mesmo contexto o presente trabalho apresenta os resultados preliminares de projeto de pesquisa em curso, desenvolvido pelos autores junto à Universidade do Estado de Minas Gerais, que tem foco em promover a atuação do design na valorização da cultura gastronômica de um território suas diversidades e qualidades interconexas que reforçam o interesse exploratório desta pesquisa, bem como as consequências atuais e principalmente futuras a propósito das "diversidades" que são os pontos de interesse nesse estudo.

O emprego dos métodos e das ferramentas da área de design, voltados para fortalecer e potencializar a economia criativa, assumem valor estratégico ao considerar conjuntamente fatores humanos, sociais e econômicos de um território, que se relacionam também à sua capacidade criativa e produtiva. Essa abordagem busca identificar e evidenciar referências fundamentais nos processos de ativação, promoção e difusão da inovação sob um ponto de vista humanístico, nos quais emergem especificidades peculiares ao território, em contínua construção entre seus atores, sujeitos e o meio. 


\section{AGRADECIMENTO}

Ao CNPq - Ministério da Ciência e Tecnologia e ao Ministério da Cultura pelo apoio financeiro por meio do Edital 80/2013 de Economia Criativa. À Escola de Design da UEMG e ao Programa de Pós Graduação em Design pelo apoio institucional.

\section{REFERÊNCIAS}

ATALA, Alex. Site do Instituto ATÁ. Disponível em: <http://www.institutoata.org.br>. Acesso em: $<17$ de março de 2014>

BARRETO, Luiz. Economia Criativa e a Copa do Mundo. In: OBJETO BRASIL. Um novo Olhar Sobre o Design Brasileiro. São Paulo: Senai-SP editora; Associação Objeto Brasil, 2012.

BELLARDI, R.; KRUCKEN, L.; MORAES, D. 2010. Valorização de Produtos do Setor de Laticínios do Território de Minas Gerais através do Design: uma Pesquisa Exploratória. Fórum das Américas: Leite e Derivados $-8^{\circ}$ Congresso Internacional do Leite. Juiz de Fora, 2010.

EATALY. Site da Eataly. Disponível em <http://www.eataly.com>. Acesso em: $<20$ de março de 2014>

FRANZATO, C.; KRUCKEN, L. ; REYES, P. B. 2013. Design for territorial development in emerging economies: Brazilian experiences of research and teaching. Strategic Design Research Journal, v. 6, p. 11-19, 2013.

GRANDMA'S design. Site do Grandma's Design. Disponível em: http://www.grandmasdesign.com Acesso em 13 de Maio de 2014

HOWKINS, John. Economia Criativa: como ganhar dinheiro com ideias criativas. São Paulo: M.Books do Brasil, 2013.

NACCACHE, Andréa. Criatividade Brasileira: Alex Atala, Fernando e Humberto Campana, Jum Nakao: gastronomia, design, moda. Barueri: Manole, 2013.

KRUCKEN, Lia. Design e território: valorização de identidades e produtos locais. São Paulo: Nobel, 2009.

KRUCKEN, L.; BRITTO, A. M.; FRANZATO, C. 2013. Strategic Design Applied to Terroirs. A Co-Design Experience Aimed at Adding Value to a Brazilian Genuine Local Cheese. In Proceedings $2^{\text {nd }}$ International Conference Agrindustrial Design. Izmir: Izmir Economics University, v. 1. 2013. p. 199-212.

LA JEUNE rue. Disponível em: http://lajeunerue.com/ Acesso em 13. Mar. 2014.

LA JEUNE rue paris gastronomy village by Cedric Naudon and powerhouse line-up of designers. Disponível em: http://www.designboom.com/design/la-jeune-rue-parisgastronomy-village-by-cedric-naudon-and-powerhouse-line-up-of-designers-01-27-

2014/ Acesso em 08 de mar. 2014.

LAVALLE, Rodrigo. Paris e seu projeto ambicioso gastronômico/design "La Jeune Rue". Disponível em: <http://www.conexaoparis.com.br/2014/02/27/paris-e-seu-projetoambicioso-gastronomicodesign-la-jeune-rue/> acesso em 8 de Mar. 2014

PRESENTATION du Projet la Jeune Rue. Disponível em: $<$ http://www.saywho.fr/mondanites/3342/presentation-du-projet-la-jeune-

rue/172971> Acesso em 08 mar. 2014 
ZARA, Janelle. La Jeune Rue, une rue design à Paris. Blouin Artinfo. Disponível em http://fr.blouinartinfo.com/news/story/1004887/la-jeune-rue-une-rue-design-a-paris acesso em 08 de mar. 2014 